\title{
UN NUEVO TRÍMETRO DE SOLÓN
}

The author of this paper identifies a yambic trimeter by Solon in a passage of Aristotle's Athenaion Politeia. Although there is no litteral quotation, the slight modifications Aristotle has introduced in it in order to adapt it to his prose do not prevent the establishment of the original text.

Durante unas recientes jornadas sobre textos griegos ${ }^{1}$ el profesor $\mathrm{H}$. Kuch, en el coloquio que siguió a la comunicación presentada por el profesor J. A. Fernández Delgado con el título «El yambo 36 West de Solón: la poesía al poden ${ }^{2}$, llamó la atención sobre el carácter especial que presenta la palabra $\sigma \varepsilon ı \sigma \alpha ́ \chi \theta \varepsilon ı \alpha \nu$ que en el texto de la Constitución de los atenienses (XII 4) de Aristóteles precede inmediatamente a los versos de Solón que constituyen el fragmento 36 de la edición de West ${ }^{3}$. Señalaba el profesor Kuch que la palabra no parece haber sido empleada por Aristóteles sin más, sino que éste ha de haberla tomado de Solón.

La palabra $\sigma \varepsilon ı \sigma \alpha ́ \chi \theta \varepsilon ı \alpha$, en efecto, no se documenta en el resto de la obra de Aristóteles salvo otras dos veces en la propia Constitución de los atenienses, en los párrafos VI 1 y VI 2. Pero es más, en el conjunto de la literatura griega antigua ${ }^{4}$ sólo aparece en doce pasajes más ${ }^{5}$ además de los ya citados. Estos son los siguientes ${ }^{6}$ : Androtio 34, Heraclid. Lemb. Pol. 3, D. S. I 79, Plu. Mor. 343 C, Plu. Mor. 807 D, Plu. Sol. 15, Plu. Sol. 16, Plu. Luc. 20, Plu. Caes. 37, Hdn. Epim. 126, 3, Hdn. Gr. II 579, 17 y D. L. I 45. De todos los pasajes

\footnotetext{
1 IV Jornadas Internacionales de Estudios Actuales sobre Textos Griegos, celebradas en Madrid del 27 al 30 de octubre de 1993, organizadas en el Área de Filología Griega de la UNED y coordinadas por el Dr. J. A. López Férez.

${ }^{2}$ En prensa en las actas de las jornadas mencionadas en la $\mathrm{n}$. anterior.

3 Diehl 24, Adrados 24, Gentili-Prato 30.

4 Para una revisión sistemática nos hemos servido del CDROM D del Thesaurus Linguae Graecae de la Universidad de Irvine.

5 Sin contar los testimonios de los lexicógrafos antiguos. Éstos pueden verse en A. Martina, Solon (testimonia veterum), Roma 1968, pp. 144-146.
} 
citados once ${ }^{7}$ contienen referencias directas a Solón, de lo que, de entrada, se deduce que la palabra no fue de uso general en la antigüedad griega, sino que se empleaba específicamente para referirse a uno de los aspectos de la actividad legislativa de Solón, concretamente la condonación de deudas y la liberación de aquellos que habían llegado a la esclavitud por deudas ${ }^{8}$.

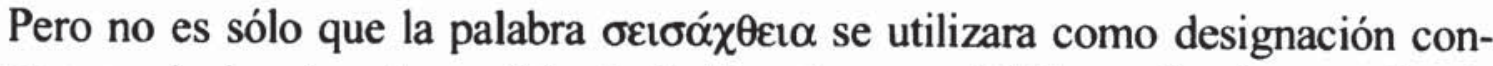
creta y exclusiva de esta medida de Solón, sino que debió ser él mismo quien la acuñara ${ }^{9}$, según testimonian algunas de las fuentes mencionadas. Así, en D. S. I

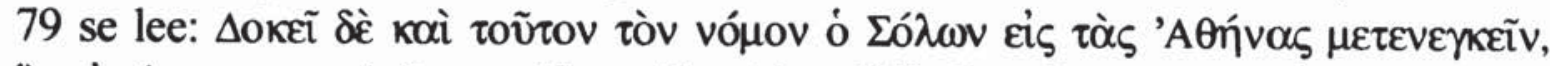

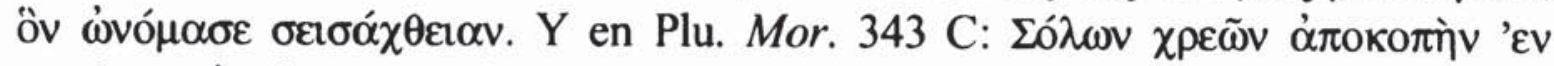

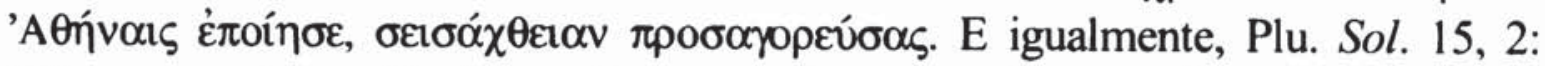

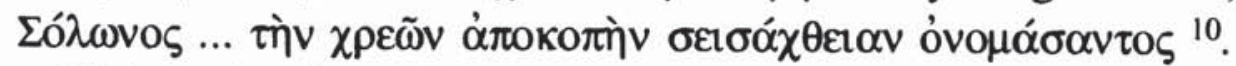

Volviendo al análisis de la frase que en Arist. Ath. XII 4 precede al fragmento de Solón al que me refería más arriba, nos encontramos con que el final de la misma presenta la siguiente métrica:

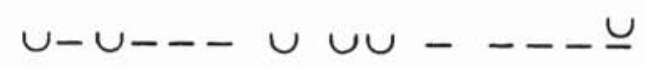

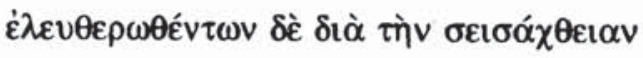

Como se observa no resulta difícil constatar que aquí subyace un trímetro yámbico apenas encubierto por Aristóteles. En efecto, basta con eliminar la preposición $\delta ı \alpha ́$ y sustituir $\sigma \varepsilon \imath \sigma \alpha ́ \chi \theta \varepsilon \iota \alpha \nu$ por $\sigma \varepsilon \imath \sigma \alpha \chi \theta i ́ \eta v$ para obtener esta secuencia:

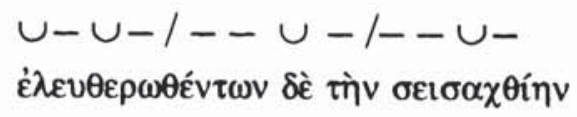

${ }^{6}$ A lo largo de todo el artículo seguimos para las citas las abreviaturas y ediciones utilizadas por el Diccionario Griego-Español.

7 Arist. Ath. VI 1, Arist. Ath. VI 2 y Arist. Ath. XII 4, Androtio 34, Heraclid. Lemb. Pol. 3 , D. S. I 79, Plu. Mor. 343 C, Plu. Mor. 807 D, Plu. Sol. 15, Plu. Sol. 16 y D. L. I 45.

${ }^{8}$ Por lo que se refiere a los cuatro pasajes restantes en que está atestiguada la palabra, los dos de Herodiano (Hdn. Epim. 126, 3 y Hdn. Gr. II 579, 17) hacen referencia únicamente a cuestiones de prosodia, por lo que no son significativos para la interpretación de la palabra. Los dos de Plutarco (Plu. Luc. 20 y Plu. Caes. 37) hacen referencia a otras acciones de cancelación de deudas, no a la llevada a cabo por Solón. Sin embargo, no creo que esto justifique llegar a la conclusión de que la palabra podía aplicarse a cualquier medida de este tipo. Más bien hay que pensar que Plutarco, en estos dos pasajes, utilizó la palabra a sabiendas de su especificidad para designar esa acción legislativa de Solón, con las connotaciones consiguientes. Además, por lo que atañe a la biografia de César parece que fue escrita con posterioridad a la de Solón (v. pp. 78-85 de la introducción general de A. Pérez Jiménez a Vidas paralelas, vol. I, Madrid, 1985).

9 Esta idea se encuentra ya en W. J. Woodhouse, Solon the Liberator, Nueva York 1965, p. 169: «It would seem, then, that the word 'Seisachtheia' was Solon's own coinage.» Sin embargo, no ofrece de forma completa los argumentos para realizar tal afirmación.

$10 \mathrm{Y}$ en el mismo sentido, si bien no de forma tan explícita, parece apuntar el testimonio de Arist. Ath. VI 1, Heraclid. Lemb. Pol. 3, Plu. Mor. 807 D y D. L. I 45. 
Tal secuencia constituye un trímetro yámbico perfecto, con censura heptemímera y que cumple la ley de Porson. Creemos que resulta razonable atribuir este trímetro a Solón. No obstante, es necesario ofrecer los argumentos que justifican las correcciones que hemos propuesto.

Por lo que se refiere a la preposición $\delta$ ió, su inclusión por parte de Aristóteles se debe a que ha de adaptar el trímetro de Solón a la sintaxis que exige la oración en la que lo ha insertado ". Sin añadir la preposición hubiera resultado imposible

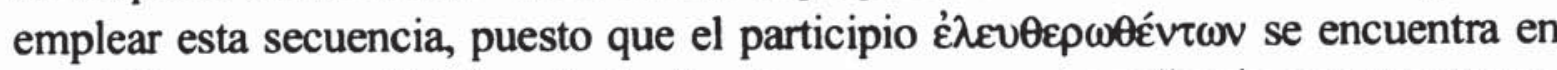
aposición a otro participio, $\tau \tilde{\omega} v \delta 0 v \lambda \varepsilon v o ́ v \tau \omega v$, a su vez coordinado con un sustan-

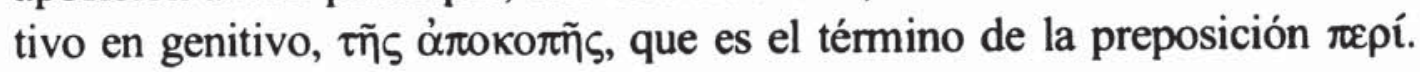

En cuanto a la corrección de $\sigma \varepsilon \imath \sigma \alpha ́ \chi \theta \varepsilon \varepsilon \alpha \nu$ en $\sigma \varepsilon ı \sigma \alpha \chi \theta i ́ \eta v$, me parece plenamente justificable por lo siguiente. Solón en una composición lírica nunca hubiera empleado un sustantivo en - $\varepsilon 1 \alpha$, sino en -ín. El análisis de los versos que de él han llegado hasta nosotros así lo revela, pues en ellos no se docu-

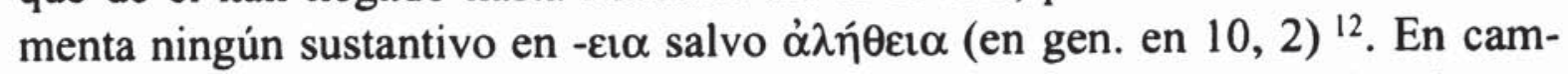
bio, los sustantivos con el segundo de los sufijos mencionados son abundantes:

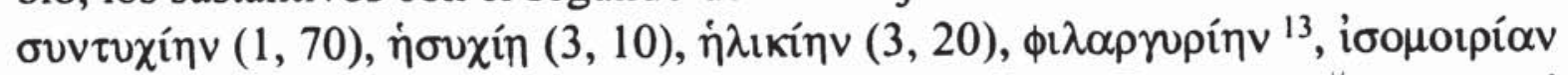
$(23,21)$, etcétera. A pesar de que presenta el sufijo $-\varepsilon l \bar{\alpha}$ y no $-\varepsilon i \alpha$, que es el que directamente interesa aquí, me parece especialmente significativo el caso

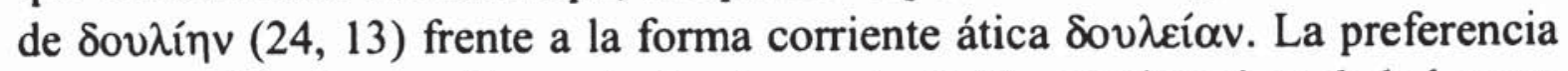
por este sufijo -ín constituye, dentro de una tradición continuadora de la lengua poética forjada por la épica, uno más de los rasgos jonios de la lengua literaria de Solón ${ }^{14}$, pues, como señala P. Chantraine ${ }^{15}$, «la finale $-\varepsilon 1 \alpha$ s'est d'autre part trouvée en concurrence avec la finale $-i \bar{\alpha}$. L'ionien en particulier présente un grand nombre de dérivés en -ín répondant à des dérivés en - $\varepsilon 1 \alpha$ de l'attique».

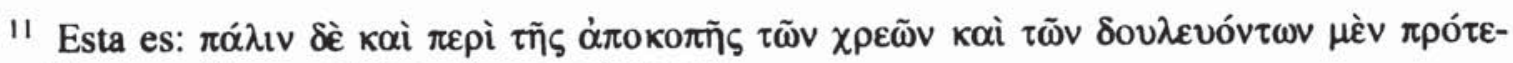

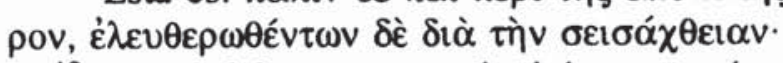

12 Otra palabra que en principio parecería que presenta este sufijo es $\dot{\alpha} \mathrm{i} \rho \operatorname{cin}(12,4)$. De entrada se trata de una palabra ya homérica que Solón podría haber tomado tal cual, pero es que, además, es muy probable que en esta palabra no tengamos que ver en realidad dicho sufijo, sino $\varepsilon$ como mera grafia de $i$ (v. P. Chantraine, La formation des noms en grec ancien, París 1933, p. 87).

${ }^{13}$ Así Adrados según la conjetura de Kenyon. Gentili-Prato (5.1), en cambio, leen $\phi 1-$ $\lambda o \chi \rho \eta \mu \alpha \tau i \alpha$ siguiendo el testimonio de Plu. Sol. 14, 2 (otras conjeturas pueden verse en el aparato crítico de esta última edición.). La restitución propuesta por Gentili-Prato me parece muy sugerente, salvo en el hecho de mantener los finales en -i $\alpha$ que nos transmiten Arist. Ath. V y Plu. l.c., frente a las formas en -ín que ofrece la edición de Adrados, opción que creo mucho más acertada ya que ésta es la forma que con mucho predomina en los versos citados en las fuentes explícitamente como tales.

14 Sobre la lengua de Solón pueden verse las pp. 138-142 de F. R. Adrados, «Sobre los orígenes del vocabulario áticon, EMERITA 21, 1953, pp. 123-162.

is Op. cit., p. 88. 
Por todo lo dicho parece razonable pensar que, efectivamente, hay que atribuir dicho trímetro a Solón. El proceso que ha tenido lugar ha consistido en que Aristóteles, bien teniendo delante el texto del poema de Solón, bien citando de memoria, al intentar dar una idea rápida del contenido del poema ha incluido un verso del mismo pero adaptándolo ligeramente a su prosa, frente a la cita ya explícita de versos que viene a continuación.

La identificación de esta secuencia como de Solón resulta de gran interés, no ya sólo por permitir que aumente nuestro conocimiento directo de su obra poética, que en tan escasa medida nos ha sido transmitida, sino también por sus implicaciones de índole literaria e histórica.

Desde el punto de vista literario, permite afrontar desde una nueva perspectiva el problema largamente debatido de si el texto del yambo 36 West constituye un poema completo o no ${ }^{16}$. La aparición de un $\delta \dot{e ́ ~ a l ~ i n i c i o ~ y a ~ h a b i ́ a ~ s i d o ~ s e n ̃ a l a d a ~}$ por algunos autores como prueba de que hubo algunos versos que precedían a los transmitidos que no nos han llegado. Creo que los que así pensaban estaban en lo cierto. La identificación que he propuesto de este nuevo verso de Solón viene a corroborarlo, ya que me parece que hay que pensar que se trata de un trímetro del mismo poema de Solón que aquel al que pertenecen los versos explícitamente citados por Aristóteles como tales a continuacón de la secuencia que hemos venido analizando. En efecto, la estructura en la que se insertan las citas de versos de Solón por parte de Aristóteles en el capítulo 12 de la Constitución de los atenienses se muestra bastante clara: Aristóteles va aludiendo a diferentes aspectos de la actividad política de Solón y los va ilustrando con citas representativas entresacadas de diferentes composiciones del propio Solón. Caracterizados desde el punto de vista formal por estar introducidos todos (a partir del segundo) por un $\pi \alpha^{\prime} \lambda_{l v}$ que funciona a modo de marca de los diferentes ítems que se repasan, los encabezamientos que Aristóteles va anteponiendo a cada una de estas citas vienen a ser así una síntesis de la temática del poema del que Aristóteles ha extraído la cita que sigue. En este sentido no es de extrañar que Aristóteles haya incluido casi literalmente un verso del mismo pertenenciente a la parte que ha dejado sin citar.

Desde el punto de vista histórico la identificación de este trímetro sirve para matizar algunos problemas referentes al contenido concreto de la $\sigma \varepsilon ı \sigma \alpha ́ \chi \theta \varepsilon\llcorner\alpha$ soloniana. Aunque las fuentes antiguas ${ }^{17}$ y los estudiosos modernos ${ }^{18}$ inter-

16 Para una toma de posición y un interesante comentario general acerca de dicho fragmento puede verse E. García Novo, «Fuerza y justicia», CFC 16, 1979-80, pp. 199-213.

17 V. A. Martina, op. cit., pp. 141-6.

18 V. por ejemplo, K. Höhn, Solon, Viena 1948, pp. 73-78 y n. 84 en p. 207; W. J. Woodhouse, op. cit., pp. 167-179; H. Hommel, «Solon -Staatsman und Dichten,, en G. Pfohl (ed.), Die griechische Elegie, Darmstadt 1972, pp. 236-262, especialmente pp. 252-3; A. Bonnard, Civilisation Grecque, vol. I, De l'Iliade au Parthénon, Bruselas 1991, p. 125. 
pretan mayoritariamente que la medida consistió en una cancelación general de deudas y la consiguiente liberación de aquellos que se habían visto reducidos a la esclavitud por el impago de las mismas, ya algunos autores antiguos, como Androción ${ }^{19}$, pusieron en tela de juicio la radicalidad de esta medida y supusieron que la $\sigma \varepsilon ı \sigma \alpha ́ \chi \theta \varepsilon ı \alpha$ no consistió sino en una regulación más justa de los tipos de interés. Esta interpretación no se sostiene a la vista del sintagma

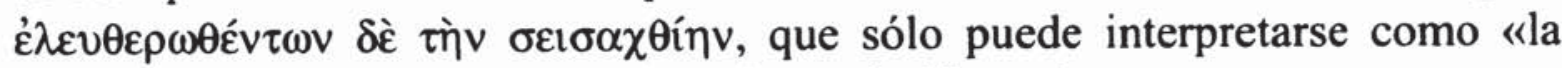
condonación de deudas de los devueltos a la libertad».

Eugenio Ramón LuJán Martínez

19 Androtio 34. 